\title{
A influência da ferramenta digital "Google Tradutor" no processo de aprendizagem de língua inglesa
}

\section{The influence of the digital tool "Google Translate" in the English learning process}

\author{
Thaís Bernardes Costa
}

\begin{abstract}
Resumo: Prensky (2001) afirma que a nova geração de alunos está habituada ao uso de tecnologias e a receber e assimilar informações rapidamente, esses sujeitos são nomeados "nativos digitais". A aprendizagem de língua inglesa nesse contexto digital tem se justificado, principalmente, pelo status de língua global e por ser um instrumento de comunicação entre diferentes culturas. Dessa maneira, propomos analisar o processo de aprendizagem de língua inglesa através da ferramenta online "Google Tradutor" por um nativo digital de uma escola municipal de Uberaba (MG). Para tal propósito, recorremos ao conceito de affordance (GIBSON, 1986), utilizado na área de Linguística Aplicada, que diz respeito às diferentes formas como o indivíduo utiliza e percebe um ambiente. Sendo assim, acreditamos que os ambientes online são propícios para a efetivação de diferentes affordances. Além disso, Benson (1997) afirma que ambientes extraclasse (defendemos que isso inclui a internet) contribuem para a autonomia na aprendizagem. Através de questionários e de uma entrevista com um aprendiz de língua inglesa, concluímos que ele percebe e efetiva diferentes affordances por meio do "Google Tradutor". Percebemos ainda que esse aprendiz, foco do estudo, mostra indícios de autonomia e de 'não-autonomia' na sua aprendizagem de língua inglesa.
\end{abstract}

Palavras-chave: Língua Inglesa; Google Tradutor; aprendizagem; affordances; autonomia.

Abstract: Prensky (2001) claims that the new generation of students is accustomed to the use of technologies and to receive and assimilate information quickly, these people are named as "digital natives". The learning of the English language in this digital context is justified, mainly, by its status as a global language and be considered as an instrument of communication among different cultures. Thus, we propose to analyze the English learning process of a native digital from a municipal school in Uberaba (MG), via the online tool "Google Translate". For this purpose, we use the concept of affordance (GIBSON, 1986), which is used in Applied Linguistics and which concerns the different ways a person perceives and uses the environment. Thus, we believe that online environments are conducive to the realization of different affordances. In addition, Benson (1997) states that extracurricular environments, and we highlight the Internet as one of them, contribute to learning autonomy. Through questionnaires and an interview with an English language learner, we have concluded that he realizes different affordances through "Google Translate". Besides, we have observed that this learner, focus of this study, shows aspects of autonomy and 'non-autonomy' in his English learning process.

Keywords: English Language; Google Translate; learning; affordances; autonomy.

\section{Introdução}

Atualmente sabemos que é comum o uso de tecnologias digitais de informação e comunicação (TDIC) para auxiliar o processo de aprendizagem de qualquer disciplina, inclusive o de língua estrangeira. O meio digital é vastamente citado em documentos oficiais, como, por exemplo, nos Parâmetros Curriculares Nacionais:

\footnotetext{
* Graduada em Letras - Português/Inglês pela Universidade Federal do Triângulo Mineiro (UFTM).
} 
É inegável que aumenta cada vez mais a possibilidade de acesso às redes de informação do tipo Internet, como também as exigências do mundo do trabalho passam a incluir o domínio do uso dessas redes. $\mathrm{O}$ conhecimento de Língua Estrangeira é crucial para se poder participar ativamente dessa sociedade em que, tudo indica, a informatização passará a ter um papel cada vez maior (BRASIL, 1998, p. 87).

Visto que a realidade da sociedade atual está repleta de elementos tecnológicos digitais (computadores, internet, celulares), os métodos e abordagens de ensino precisam acompanhar essa mudança para não serem considerados antiquados ou retrógrados. O perfil dos alunos das escolas regulares vem mudando com os anos, principalmente a partir do século 20, e o sistema educacional se esforça para acompanhá-los, porém ainda há um longo caminho para se alcançar o êxito.

A grande maioria dos aprendizes está ambientada com diversas tecnologias digitais de informação e comunicação, portanto podem ser considerados, de acordo com Prensky (2001), "nativos digitais". Assim, torna-se cada vez mais necessária a inclusão de atividades envolvendo esses recursos em sala de aula. As instituições de ensino, que no início enxergavam esse avanço tecnológico como ameaça e dispersor da atenção do aluno, já começam a explorar mais as diversas ferramentas que as tecnologias digitais oferecem a favor da educação.

Durante o período de observação do estágio supervisionado de Língua Inglesa no Ensino Fundamental, obrigatório no Curso de Letras da UFTM, pudemos observar o quanto as escolas buscam integrar a tecnologia ao ensino. $\mathrm{Na}$ escola-campo, na qual conduzi meu estágio, pertencente à rede municipal de ensino de Uberaba (Minas Gerais), existe um projeto chamado "Um computador por aluno" (Projeto UCA), no qual cada indivíduo matriculado na instituição recebe um netbook. Esse material pode ser usado em sala de aula conforme o professor determine em seu planejamento, além disso, o objeto pode ser levado para casa pelo aluno para a realização de atividades extraclasse.

A partir dessas observações, iniciamos com a principal inquietação que conduziu à realização desta pesquisa. Durante esse período de estágio, alguns alunos disseram que usavam ferramentas da internet para auxiliar na aprendizagem da língua estrangeira. Dentre esses aprendizes, um aluno - nomeado nesta pesquisa como João - se destacava. Esse aprendiz, durante as aulas, respondia a todas as perguntas acerca de vocabulário feitas pela professora, além de, na maioria das vezes, alcançar notas boas em suas 
avaliações. Diversas vezes era questionado o lugar no qual ele aprendia as novas palavras, e sua resposta era sempre a mesma: Google Tradutor ${ }^{1}$. Portanto, a partir desse caso, surgiu o seguinte questionamento: como essa ferramenta contribui para a construção da aprendizagem de língua inglesa desse aprendiz?

Sendo assim, esse estudo justifica-se, inicialmente, pela importância da tecnologia na aprendizagem, visto que os aprendizes estão cada vez mais adeptos ao uso de recursos tecnológicos digitais. Assim, a familiaridade digital desses indivíduos precisa ser levada em conta para que o ensino se torne mais agradável e parta da realidade deles.

Objetivamos analisar: primeiramente, quais as características desse aprendiz de língua inglesa que busca aprender por meio dessa ferramenta tecnológica e quais os propiciamentos $^{2}$ efetivados por esse aprendiz que o auxiliam no processo de aprendizagem de língua inglesa através do uso da ferramenta Google Tradutor; e, em um segundo momento, se o uso dessa ferramenta o constitui como sujeito autônomo em sua aprendizagem de língua inglesa.

Para nortear este estudo, abordamos o conceito de "nativo digital" a partir de Prensky (2001). Posteriormente, dividimos nossa base teórica em duas seções: a primeira voltada para o conceito de "propiciamento" (ou affordance) de acordo com Gibson (1986), Van Lier (2004) e Paiva (2006, 2008, 2009, 2010). Na segunda parte, abordamos a questão da autonomia na aprendizagem de língua inglesa conforme as obras de Benson (1997), Dickinson (1987), Little (1991) e Littlewood (1996).

\section{Fundamentação teórica}

\subsection{O contexto da geração digital}

Devido ao crescente contato com novas tecnologias, as novas gerações iniciaram-se em um mundo diferente. Prensky (2001, p. 1) afirma que o perfil dos estudantes mudou radicalmente, "os aprendizes de hoje pensam e processam informações diferentemente de seus antecessores" 3 (grifo do autor). Além disso, o modelo de educação atual não está completamente adequado a isso, pois não foi

\footnotetext{
1 “Google Tradutor" ou "Google Translate" é um serviço virtual gratuito da empresa Google Inc. de tradução instantânea de textos e websites.

${ }^{2}$ Termo traduzido por Paiva (2009), cuja concepção será posteriormente discutida neste texto.

${ }^{3}$ Essa e as demais traduções são de minha responsabilidade.
} 
desenvolvido para eles. A partir dessa discussão, temos duas gerações: a dos "nativos digitais", indivíduos que nasceram nesse mundo digital e estão ambientados a essa nova linguagem tecnológica relacionada a computadores, videogames e jogos on-line, e, principalmente, à internet.

Com o advento dos novos meios de comunicação de massa, a consolidação da economia sem fronteiras, a facilidade no deslocamento de pessoas e, consequentemente, o contato entre culturas diferentes, fez-se necessária uma língua falada em todo o mundo para contribuir com uma comunicação eficiente. Por esse motivo, a língua inglesa recebeu o status de língua global.

Nesse sentido, Crystal (2003) afirma que língua global é a que possui um papel reconhecido em todos os países do mundo, esses devem ser vistos de duas maneiras: (a) língua usada em um país na comunicação, negócios, educação, etc., geralmente é descrita como segunda língua ou complementar da língua materna; (b) a língua inglesa tem prioridade no ensino de língua estrangeira nas escolas.

Partindo dessa ideia, podemos observar $^{\circ}$ contexto em que se aprende língua inglesa no Brasil. Trata-se de um modo relacionado a (a) e (b). O ensino de línguas estrangeiras no Brasil também está norteado pelas Orientações Curriculares Nacionais OCN (2006) para o Ensino Médio. Na parte Linguagens, Códigos e suas Tecnologias, fundamenta-se o ensino das línguas na busca do respeito à diversidade. Seu objetivo é conhecer e usar a língua estrangeira moderna como instrumento de acesso às informações e às outras/culturas e grupos sociais. Alega-se que o ensino de línguas estrangeiras deve ser pensado em termos de competências integradas, na medida em que cada língua é veículo da comunicação de uma cultura. Isso se justifica pelo fato de que a comunicação é uma ferramenta indispensável no mundo moderno para a formação pessoal, acadêmica e profissional do indivíduo.

\subsection{O conceito de affordance (propiciamento)}

Partimos de uma abordagem ecológica do ambiente utilizando o termo affordance cunhado por Gibson (1986): "as affordances do ambiente são aquilo que ele oferece ao animal, o que provê ou proporciona, mesmo sendo bom ou ruim" (GIBSON, 1986, p.127). O termo foi pensado a partir do verbo afford da língua inglesa que 
significa proporcionar, oferecer, propiciar, causar ${ }^{4}$. Através desse conceito, Gibson (1986) pretende criar a relação entre os animais e o ambiente antes não definido por nenhum termo. Ele exemplifica essa ligação a partir do formato das superfícies terrestres, nas quais dependendo do seu tipo, o homem as utiliza como tipo diferente de affordances: uma trilha na floresta te propicia caminhar e uma superfície com água te propicia nadar, etc.

Ainda, enfatiza que elas são relativas, dependendo da relação do indivíduo com o ambiente, ou seja, um mesmo local pode oferecer diferentes affordances, assim como um mesmo objeto pode ser percebido de maneiras distintas. Um exemplo dessa relação é citado por Oliveira (2011, p. 7); analisando esse excerto, observamos que a autora criou um modo próprio de utilizar seus lápis, ou seja, uma affordance:

Quando criança, eu adorava brincar de bonecas, porém, quando ia passar o dia em minha bisavó e esquecia de levá-las, utilizava meus lápis como bonecas. As cores mais femininas, como rosa e amarelo, eram as bonecas e as masculinas, como azul e verde, os bonecos. Minha bisavó nunca entendia o que eu estava fazendo com um monte de lápis e falando sozinha.

A aplicação do conceito de affordances no ambiente de aprendizagem vai muito além da utilização de material didático, envolvendo outros recursos com os quais os alunos lidam, inclusive os que possuem tecnologias digitais de informação e comunicação. Acreditamos que esse termo torna-se relevante no contexto a ser analisado, visto que nos remete ao que o ambiente virtual, no caso o "Google Tradutor", oferece ao aprendiz, facilitando a aprendizagem, ou para torná-la mais árdua.

O termo affordance tem sido cada vez mais usado na área de Linguística Aplicada. Não obstante, recentemente Paiva (2010) traduz o termo para o Português como "propiciamento" (doravante nomeado dessa forma).

Os estudos de van Lier (2004, p. 92), na mesma linha de Gibson (1986), porém voltados para a área da educação quanto à aquisição de segunda língua, partem da ideia: “em termos de aprendizagem de línguas, os propiciamentos surgem da participação e do uso, e as oportunidades de aprendizagem surgem como consequência da participação e do uso". Portanto, é a partir da relação do aprendiz com o ambiente que são efetivados diferentes propiciamentos.

\footnotetext{
${ }^{4}$ Traduções retiradas do Dicionário Oxford (2007).
} 
Van Lier (2004, p.91) define propiciamento como "aquilo que está disponível para a utilização da pessoa", ou "algo com potencial para a ação e que emerge quando interagimos com o mundo físico e social. As precondições para que o significado emirja são ação, percepção e interpretação em um ciclo contínuo de reforço mútuo”. (p.92)

Nessa mesma perspectiva, Paiva (2010) enfatiza que os propiciamentos não são propriedades dos ambientes, prova disso é o fato de cada indivíduo ter diferentes percepções do mundo e, a partir da interação que eles mantêm com esses ambientes, emergem diferentes práticas sociais, ou, no caso, formas de aprendizagem. Assim, ao pensarmos no "Google Tradutor", bem como em qualquer outra ferramenta digital, diversos propiciamentos podem ser efetivados.

\subsection{Aprendiz de língua inglesa enquanto sujeito autônomo}

Como apontado anteriormente, um dos objetivos desse trabalho é investigar se o sujeito analisado possui indícios de autonomia em sua aprendizagem de língua inglesa. A priori faz-se necessário definir tal termo, visto que não é um conceito simples. Segundo Paiva (2010) “definir autonomia não é uma tarefa fácil, porque há poucos contextos onde os aprendizes podem, realmente, ser autônomos".

A discussão desse termo iniciou-se com Henry Holec (1981) com o livro Autonomy and foreign language learning. Esse conceito estava, inicialmente, associado à independência e à individualidade de um sujeito, pois, ele assumiria a total responsabilidade pelas decisões tomadas acerca dos métodos e técnicas para desenvolver sua aprendizagem. Tal definição traça o sujeito como um autônomo ideal, portanto, utópico; além disso, não explicita como e quando se é atingido esse nível de autonomia.

Na tentativa de melhor definir o termo, Little (1991, p. 4) conceitua: “autonomia é a capacidade de planejar, monitorar e avaliar as atividades de aprendizagem, e, necessariamente, abrange tanto o conteúdo quanto o processo de aprendizagem". Portanto, não significa autodidatismo. O autônomo é aquele que reflete criticamente sobre o seu próprio processo de aprendizagem, traçando objetivos conforme necessite em determinado estágio do processo para alcançar os resultados almejados. Porém, Little (1991) enfatiza que o aprendiz não é total responsável por todo o processo, assim, a figura do professor não é dispensável. O professor pode e deve fornecer condições e estímulo para o desenvolvimento da autonomia no aprendiz. 
Nessa linha, Dickinson (1987) acredita que é preciso levar-se em conta que, no caso de aprendizes de uma segunda língua, muitas vezes os materiais a serem estudados são propostos, portanto, outro indivíduo o conduziu a um caminho. Entretanto, isso não impede que o aprendiz seja autônomo. Ainda para Dickinson (1987), existem graus de autonomia relacionados ao auto-gerenciamento e às escolhas externamente dirigidas envolvendo decisão de aprender; método de aprendizagem; ritmo; quando/onde; materiais; monitoramento; avaliação interna e externa.

Littlewood (1996) propõe a divisão da autonomia em três tipos: o indivíduo como comunicador, usando a língua adequadamente às situações comunicativas -0 uso criativo; como aprendiz, utilizando próprias estratégias de aprendizagem; e como pessoa, expressando significados e sentidos de contextos pessoais. A essas três definições Paiva (2006, p. 85) acrescenta "a autonomia como usuário de tecnologia (habilidade para usar a tecnologia, especialmente, a Internet, uma ferramenta auxiliar importante no processo de aprendizagem de LE)". Em outras palavras, é importante acrescentar a dimensão tecnológica no contexto do nativo digital, que tende a utilizar as TDIC para auxiliar no seu processo de aprendizagem.

Em se tratando de contextos externos possibilitadores de autonomia, Benson (1997) acredita que a aprendizagem da língua fora do contexto educacional pode fornecer ao aprendiz técnicas necessárias para que ele use no momento em que for adequado, constituindo uma forma de autonomia. Sendo assim, acreditamos que os ambientes virtuais através de seus diferentes recursos, podem funcionar com um ambiente propício para a autonomia. Entretanto, isso não significa que o ambiente escolar não influencia nessa atitude, pois, é possivelmente a partir desse contexto que o indivíduo busca outros recursos para complementar seu conhecimento.

\section{Metodologia}

Trata-se de uma pesquisa qualitativa, pois analisamos um contexto de determinada ocorrência juntamente com seus resultados. Além disso, possui caráter etnográfico, uma vez que os questionamentos que norteiam esse estudo partiram da vivência no cotidiano da sala de aula onde estava inserido o aprendiz de língua inglesa. Ainda, "parte da responsabilidade do etnógrafo é ir além do que os atores locais entendem explicitamente, identificando os sentidos que estão fora do alcance dos atores locais" (ASSIS-PETERSON; COX, 2001, p. 12). 
É importante ressaltar que não pretendemos apresentar generalizações, visto que analisamos apenas o caso de um aprendiz de língua inglesa. Para tanto, interpretamos os dados recolhidos de forma contextualizada e refletindo de acordo com a base teórica norteadora.

Realizamos nossa análise de acordo com os relatos feitos por esse indivíduo, tratando-se, então, de um estudo de caso. Segundo, Yin (2009, p. 3), “em resumo, o método de estudo de caso permite aos investigadores reter as características holísticas e significativas de eventos da vida real”.

A facilidade de acesso à escola campo durante a realização do estágio foi de extrema importância para a realização desse trabalho. Trata-se de uma escola pública municipal de Uberaba (MG) situada em uma região próxima á área central, porém, atende a diversos bairros da cidade. Além disso, é uma escola reconhecida e bem estruturada com ótima direção e com um corpo docente preparado. Os alunos, em sua maioria, são de classes média e baixa. O estágio era realizado todos os dias pela manhã, com a mesma professora. Portanto, o contato com três turmas de $5^{\mathrm{a}}$ série (ou $6^{\mathrm{o}}$ ano) e três turmas de $7^{\mathrm{a}}$ série (ou $8^{\mathrm{o}}$ ano) possibilitou o convite aos alunos para que respondessem o questionário base para a pesquisa.

Foram entregues aproximadamente 100 questionários, porém somente 29 devolveram os questionários respondidos, alguns de maneira incompleta ou rasurada. $\mathrm{O}$ questionário objetivou levantar várias características desses alunos. Este instrumento de pesquisa foi desenvolvido por um grupo de pesquisadores intitulado GELED ${ }^{5}$, do qual participamos, e, posteriormente adaptado para esta pesquisa. Devido a isso, algumas questões não foram abordadas ou levadas em consideração nesta pesquisa.

De acordo com as respostas e os objetivos dessa pesquisa, haviam duas perguntas-chave da parte intitulada "aplicativos possibilitados pelo computador e pela internet":

"Em relação ao aplicativo ou similar, escreva: (0) nunca usei (1) usei uma vez (2) usei algumas vezes (3) uso frequentemente."

Abaixo seguiam as imagens e logomarcas das ferramentas para que fossem assinaladas, dentre elas, Google, Orkut, Facebook, etc. E, a pergunta seguinte:

"Escolha 2 desses aplicativos e conte para nós alguma experiência positiva ou negativa que teve ao usar esses aplicativos. Dentre as experiências, tente

\footnotetext{
${ }^{5}$ Grupo de Estudos em Linguagem e Educação Digital.
} 
lembrar se alguma delas envolveu o uso de outra língua que não seja o português. Faça um relato e conte para nós sobre essas experiências".

Ressaltamos que o objetivo principal dessas duas questões era analisar se esses alunos demonstrariam características comuns ao conceito de "nativo digital'.

A maioria respondeu a essas duas perguntas, porém, um questionário, após as análises das repostas, se destacou por pertencer a um aluno "destaque" durante as aulas de Língua Inglesa. Trata-se de um indivíduo que demonstrava interesse em aprender a língua, e, durante as aulas, constantemente citava a ferramenta digital a qual ele utilizava, isso se confirma em suas repostas no questionário no qual ele cita o "Google Tradutor" para aprender a língua alvo.

Como segunda etapa da pesquisa, focalizamos esse aluno. Nosso objetivo foi descobrir qual a relação dessa ferramenta digital com a sua aprendizagem, se age de maneira positiva e/ou negativa, e se faz ter autonomia sob sua aprendizagem. Para tanto, foi elaborado um questionário norteador para realizamos uma entrevista com o referido aluno por meio digital.

Nessa entrevista, fizemos as oito perguntas do questionário supracitado e mais algumas pertinentes ao longo do diálogo. Esse material foi colhido através de um programa de conversação online, o Microsoft Messenger, a fim de que pudéssemos registrá-la como arquivo de texto, mantendo as respostas originais do participante, não fazendo alterações em sua grafia. Mantendo a ética da pesquisa, omitiremos o nome do aluno, substituindo pelo pseudônimo João.

$\mathrm{Na}$ próxima seção apresentamos as análises feitas durante a pesquisa. Primeiramente, o estudo acerca das repostas do João às duas perguntas do questionário impresso e, posteriormente, a análise da entrevista.

\section{Análises}

\subsection{Respostas de todos os questionários}

Nessa primeira seção, focamos na análise dos 29 questionários colhidos nas turmas de $5^{\mathrm{a}}$ série ( $6^{\circ}$ ano) e $7^{\mathrm{a}}$ série ( $8^{\circ}$ ano) do ensino fundamental da escola já citada anteriormente. Buscamos, portanto, encontrar padrões semelhantes nas respostas.

Analisando esses primeiros dados coletados, verificamos que o grupo é composto por 19 aprendizes do sexo feminino e 10 do sexo masculino, corroborando 
com Prensky (2001) em relação ao nativo digital no qual o autor afirma que não há distinção de gênero. Além disso, não seria possível estabelecer essa diferenciação nesse estudo devido à quantidade de meninas ser consideravelmente maior do que a de meninos. A idade dos alunos manteve-se entre 11 e 13 anos.

Outro dado interessante, grande parte - 21 aprendizes - possui computador em casa conectado à internet. Esse fator pode ter contribuído diretamente para a natividade digital desses alunos, pois acreditamos que o maior contato com o computador resulta em um nível de natividade diferente daqueles que não o possuem.

A classificação dos nativos digitais gerou uma variedade de características com diversas combinações, tornando difícil um padrão com distinções obrigatórias para que possamos generalizar um perfil sistêmico. Para demonstrar essa gama de possibilidades, apresentamos um quadro com as respostas dos alunos a uma das questões principais a esse estudo, "Em relação ao aplicativo ou similar, escreva: (0) nunca usei (1) usei uma vez (2) usei algumas vezes (3) uso frequentemente", abaixo estavam as imagens e logomarcas do Mercado Livre, Orkut, SMS, EA Games, The Sims, Twitter, Formspring, Google Earth, MSN Messenger, Facebook, Google, Youtube, Wikipédia, Skype e Email.

Quadro 1 - Questão acerca do uso de aplicativos ou similares pelos alunos

\begin{tabular}{|c|c|c|c|c|c|c|c|c|c|c|c|c|c|c|c|c|c|c|c|}
\hline \multicolumn{4}{|c|}{ Mercado Livre } & \multicolumn{4}{|c|}{ Orkut } & \multicolumn{4}{|c|}{ SMS } & \multicolumn{4}{|c|}{ EA Games } & \multicolumn{4}{|c|}{ The Sims } \\
\hline$(0)$ & (1) & (2) & (3) & (0) & (1) & (2) & (3) & $(0)$ & (1) & (2) & (3) & (0) & (1) & (2) & (3) & (0) & (1) & (2) & (3) \\
\hline 21 & 3 & 3 & 2 & 2 & 1 & 5 & 21 & 10 & 4 & 7 & 8 & 6 & 3 & 12 & 8 & 6 & 3 & 12 & 8 \\
\hline \multicolumn{4}{|c|}{ Twitter } & \multicolumn{4}{|c|}{ Formspring } & \multicolumn{4}{|c|}{ Google Earth } & \multicolumn{4}{|c|}{ MSN Messenger } & \multicolumn{4}{|c|}{ Facebook } \\
\hline$(0)$ & (1) & (2) & (3) & (0) & $(1)$ & (2) & (3) & (0) & (1) & (2) & (3) & (0) & (1) & (2) & (3) & $(0)$ & (1) & (2) & (3) \\
\hline 16 & 3 & 3 & 7 & 19 & 5 & 2 & 3 & 20 & 1 & 8 & 0 & 2 & 3 & 3 & 21 & 11 & 6 & 7 & 4 \\
\hline \multicolumn{4}{|c|}{ Google } & \multicolumn{4}{|c|}{ Youtube } & \multicolumn{4}{|c|}{ Wikipédia } & \multicolumn{4}{|c|}{ Skype } & \multicolumn{4}{|c|}{ Email } \\
\hline$(0)$ & (1) & (2) & (3) & $(0)$ & (1) & (2) & (3) & $(0)$ & (1) & (2) & (3) & $(0)$ & (1) & (2) & (3) & $(0)$ & (1) & (2) & (3) \\
\hline 0 & 0 & 1 & 28 & 0 & 0 & 1 & 28 & 5 & 6 & 11 & 7 & 21 & 5 & 2 & 1 & 6 & 1 & 9 & 13 \\
\hline
\end{tabular}

Observamos nesse quadro que o fato de afirmarem que usam frequentemente alguns aplicativos e outros nunca os usaram, não significa que não sejam nativos digitais devido à variedade das respostas. No entanto, podemos notar que alguns aplicativos são mais usados do que outros, possivelmente pela sua funcionalidade para essa faixa etária. Dentre os mais usados estão: Orkut, EA Games, The Sims, MSN Messenger, Google, Youtube, Wikipédia e Email. Portanto, utilizam mais os sites de relacionamento, pesquisas, jogos online e alguns considerados de lazer, como, por 
exemplo, o Youtube que é um site que permite que seus usuários carreguem e compartilhem vídeos em formato digital.

A pergunta seguinte do questionário aplicado, "Escolha 2 desses aplicativos e conte para nós alguma experiência positiva ou negativa que teve ao usar esses aplicativos. Dentre as experiências, tente lembrar se alguma delas envolveu o uso de outra língua que não seja o português. Faça um relato e conte para nós sobre essas experiências", foca a natividade, porém, voltada para o uso da língua inglesa no meio digital. A partir das respostas, podemos afirmar de maneira mais contundente que esses alunos são nativos digitais pela forma como descreveram utilizar os aplicativos. Observamos isso, especialmente nas seguintes respostas ${ }^{6}$ :

\section{Excerto \# 1}

Google $=$ Eu usei para entrar em sites, usei para descobrir sites, etc.

Youtube $=$ Usei para ver vídeos, ouvir música, etc. Usou o inglês mas eu não entendi nada.

\section{Excerto \# 2}

O MSN converso com os meus amigos e o Orkut eu brinco muito na colheita feliz. ${ }^{7}$

Através das respostas observamos que eles não relataram, em nenhum momento, dificuldades de utilização, ou seja, isso demonstra característica própria da facilidade com as novas tecnologias de um nativo digital. Os alunos servem-se dessas ferramentas da forma que melhor lhe convêm em determinada situação, utilizando-as ou não para a aprendizagem de língua inglesa, como, por exemplo, no excerto 2 no qual o aprendiz utiliza a rede social Orkut também para jogar jogos online. Portanto, podemos notar que se trata da efetivação de diferentes propiciamentos, e, ainda, concordando com Paiva (2010) que propiciamentos não são propriedades dos ambientes, partindo, assim, de cada ser individualmente. Podemos observar isso de forma mais evidente no seguinte excerto:

\section{Excerto \# 3}

uma vez o Justim Bieber postou uma coisa no twitter e usei o Google

\footnotetext{
${ }^{6}$ As respostas estão transcritas conforme foram escritas nos questionários, não foram realizadas correções ortográfica ou gramatical.

${ }^{7}$ Colheita Feliz é um simulador de fazenda em tempo real disponível como aplicativo na rede social Orkut. O jogo permite que os membros possam gerir uma fazenda virtual que inclui o plantio, cultivo e colheita de diversas plantas, árvores e animais e até mesmo o roubo.
} 
tradutor para traduzir o que ele tava dizendo.

A aluna em questão utilizou a ferramenta Google Tradutor, foco desse estudo, para um fim extremamente pessoal, entender o que um artista do qual ela gosta quis dizer em sua língua materna, pois não possuía conhecimento necessário sobre a língua para entendê-lo. Assim, efetivando um propiciamento.

Quanto aos relatos de experiências negativas, apenas dois alunos se expressaram:

\section{Excerto \# 4}

Twitter - ele é um aplicativo todo em englês e precisa de alguns aprendidos fora do computador

seu ponto negativo é que nós comunicamos em português mais é melhor.

\section{Excerto \# 5}

O twitter usei a língua inglesa quando fui se comunicar com um colega de Internet la dos Estados Unidos, pois a conversa foi rápida, porque não sei falar muito em inglês. O EA games no jogo The sims foi quando estava jogando e eu não conseguia se locomover pois não sabia os comandos em inglês.

Podemos perceber que os pontos negativos relatados não estão relacionados a dificuldades encontradas na utilização dos aplicativos ou em aspectos da natividade digital, mas sim na língua inglesa. É preciso levar em consideração que, nessas turmas, os aprendizes estão iniciando seu processo de aprendizagem da língua em questão, pois, nas escolas municipais de Uberaba o ensino de Inglês inicia-se na $5^{\mathrm{a}}$ série ( $6^{\circ}$ ano), com somente duas aulas por semana. Como o explicitado nas respostas, os alunos não possuem conhecimento necessário para manter uma conversa ou se expressar de forma concisa nessa língua, tornando-se assim barreira para a sua utilização. Ainda, o aluno do excerto 4, demonstrou perceber os propiciamentos e lamenta não ter tido a oportunidade de usar a língua inglesa nesse ambiente.

Direcionando para o uso do Google Tradutor, dentre as respostas a essa pergunta, 18 alunos, inclusive o aluno João, relataram o uso dessa ferramenta. As respostas obtidas foram semelhantes, os aprendizes relataram que a utilizam para traduzir palavras ou termos que não compreendem, tanto para ampliar seu vocabulário em língua inglesa, quanto para realizar trabalhos escolares:

Excerto \# 6

Google tradutor foi positivo pq eu aprendi palavras em inglês e me ajudou 
no trabalho de inglês.

\section{Excerto \# 7}

O Google me ajudar a traduzir línguas extrangeiras.

Assinalamos que os alunos têm consciência de que a utilização dessa e de outras ferramentas da internet auxilia no processo de aprendizagem de língua inglesa, porém, apesar da descrição do excerto 6, eles não estabeleceram uma ligação entre o que foi adquirido durante o uso delas e o que foi estudado na escola regular. Porém, durante nossa observação, percebemos que um aluno contrastava com essa asserção, trata-se, portanto do estudo das próximas seções.

\subsection{Questionário do aluno João}

Após a análise dos questionários coletados nas turmas, nesta seção apresentamos somente as respostas do aluno João, para, posteriormente compararmos com a entrevista realizada. Trata-se, como já citado, de um aluno da $5^{\text {a }}$ série $\left(6^{\circ}\right.$ ano) do ensino fundamental com 11 anos. Durante as observações do estágio supervisionado, ele apresentava grande interesse e participava ativamente, além de possuir um vocabulário mais rico comparado com os demais alunos e, também, obtinha ótimas notas nas avaliações. Em seu questionário, João afirmou não frequentar nenhum tipo de curso de línguas fora da escola regular, o que nos deu maior convicção de que seu conhecimento da língua inglesa provinha de alguma prática extraclasse.

Abaixo, suas respostas à pergunta sobre a frequência de uso dos aplicativos:

Quadro 2 - Questões acerca do uso de aplicativos ou similares pelo aluno João

\begin{tabular}{|c|c|c|c|c|}
\hline Mercado Livre & Orkut & SMS & EA Games & The Sims \\
\hline (0) nunca usei & $\begin{array}{c}\text { (3) uso } \\
\text { frenquentemente }\end{array}$ & $\begin{array}{c}\text { (2) usei algumas } \\
\text { vezes }\end{array}$ & $\begin{array}{c}\text { (3) uso } \\
\text { frequentemente }\end{array}$ & $\begin{array}{c}\text { (3) uso } \\
\text { frequentemente }\end{array}$ \\
\hline Twitter & Formspring & Google Earth & MSN Messenger & Facebook \\
\hline (0) nunca usei & (0) nunca usei & (0) nunca usei & $\begin{array}{c}\text { (3) uso } \\
\text { frequentemente }\end{array}$ & (0) nunca usei \\
\hline Google & Youtube & Wikipédia & Skype & Email \\
\hline $\begin{array}{c}\text { (3) uso } \\
\text { frequentemente }\end{array}$ & $\begin{array}{l}\text { (3) uso } \\
\text { frequentemente }\end{array}$ & $\begin{array}{c}\text { (2) usei algumas } \\
\text { vezes }\end{array}$ & (0) nunca usei & $\begin{array}{c}\text { (3) uso } \\
\text { frequentemente }\end{array}$ \\
\hline
\end{tabular}


Como observamos nas respostas acima, o aprendiz utiliza diversos aplicativos, porém de grupos temáticos semelhantes, como, por exemplo: jogos (EA Games e The Sims), ferramentas de comunicação e redes sociais (Orkut, SMS, MSN Messenger e Email), além de sites de pesquisa (Google e Wikipédia). A partir desses dados, podemos observar que os recursos tecnológicos são usados por ele em momentos de lazer e para buscar conhecimento.

Essa afirmação pode ser confirmada também pela resposta a outra pergunta: "Você acha que consegue aprender uma língua estrangeira sem estar no ambiente escolar? Como você busca o conhecimento fora da sala de aula?", cuja resposta foi:

Excerto \# 8

Busco na internete.

Assim, notamos que o meio digital é parte de seu processo de aprendizagem de língua inglesa, por ser considerado por ele como meio extraclasse de adquirir conhecimento. Parece-nos que a internet é um ambiente adequado, para ele, para gerar diferentes propiciamentos. A resposta obtida na segunda questão, na qual ele deveria relatar experiências através desses aplicativos, foi a seguinte:

Excerto \# 9

Google $=$ Para utilizar o seu tradutor

EA Games e The Sims = por que a maioria dos jogos vem em English e sou forsado a aprender.

Como podemos observar, o aprendiz confirma o uso da ferramenta, tal qual afirmamos anteriormente. Ao afirmar ser "forçado" a aprender a língua, ou seja, enxergar a necessidade de buscar alguma fonte de conhecimento para a aprendizagem nos remete à autonomia. Porém, essa breve citação do Google Tradutor não confirma nossa hipótese sobre a influência dessa ferramenta na sua aprendizagem de língua inglesa tampouco se o constitua como indivíduo autônomo nesse processo. Para tal propósito, foi realizada a entrevista.

\subsection{Entrevista com o aluno João}

Como visto anteriormente, as respostas ao questionário do aluno foco desse estudo não foram satisfatórias. Portanto, realizamos uma entrevista via programa de 
conversação online MSN Messenger. Para tanto, elaboramos um questionário que direcionará as perguntas durante a entrevista.

Iniciamos a entrevista perguntando se ele usava a língua inglesa para se comunicar, e, obtivemos uma resposta negativa. Ele afirma, ainda, que sua única oportunidade de uso da língua era durante as aulas de inglês e que, por problemas administrativos da escola, estava sem aulas da disciplina. Ao ser questionado se utilizava algum site para aprender a língua ou solucionar dúvidas sobre ela, sua resposta foi:

\section{Excerto \# 10}

Sim google tradutor

Além disso, afirma que usa frequentemente essa ferramenta, porém somente para auxiliar nos trabalhos escolares na tradução de palavras e frases. Ainda, declara ter obtido ótimas notas e, por isso, considera o uso proveitoso. Relácionado ao uso e suas dificuldades de manuseio, o aprendiz faz a seguinte consideração (doravante "P" está designado como pergunta do entrevistador e "R" como a resposta do entrevistado):

Excerto \# 11

$\mathrm{P}$ - quando você usou a primeira vez, você achou fácil ou difícil de usar?

$\mathrm{R}$ - fácil, era so digitar a palavra q eu queria e aparecia ela en ingles

Este excerto nos possibilita analisar a natividade digital desse aprendiz. Como visto, ele não encontrou obstáculos ao usar a ferramenta, julgando, até mesmo, fácil a sua utilização. Prensky (2001) afirma que os nativos digitais estão ambientados com os ambientes virtuais e tecnológicos, principalmente aqueles relacionados à internet, portanto, podemos classificar esse aprendiz como nativo digital. Ainda, o autor acredita que é possível identíficar esses nativos através da linguagem usada por eles, em outras palavras, coincide com a linguagem comum na web. Com o surgimento e maior uso da Internet, apareceram também as palavras características desse meio, tanto as dicionarizadas com função denominativa, quanto os neologismos que apenas representam certas expressões. Crystal (2001) a chama de netspeak. Trata-se de uma linguagem que incorpora neologismos, sinais tipográficos (emoticons), "variações" da norma culta ortográfica da língua, como por exemplo, a falta de pontuação e abreviação de palavras, dentre outros. Essa linguagem é usada justamente para se adequar a dinamicidade e rapidez própria do meio virtual. Essa característica é recorrente nas 
respostas do entrevistado, como podemos observar no excerto acima com na abreviação de palavras.

Ainda se tratando de natividade digital, João afirma que soube dessa ferramenta de tradução através de um colega de sala que a usava também como auxílio nos trabalhos escolares. Prensky (2001) afirma que os estudantes de hoje estão habituados a receber muitas informações, muitas vezes simultaneamente, de forma rápida, e, ainda executam múltiplas tarefas. Trabalham, portanto, melhor interligados em redes. Assim, notamos como João exemplifica essa geração digital, que se comunica e socializa seu conhecimento e suas descobertas.

Outro ponto interessante da entrevista está presente no seguinte excerto:

Excerto \# 12

$\mathrm{P}$ - alguma vez o google tradutor não te ajudou em alguma coisa?

$\mathrm{R}$ - S por que a erros nele, algumas palavras estao erradas

$\mathrm{P}$ - você consegue perceber quando estão erradas?

$\mathrm{R}$ - nao

$\mathrm{P}$ - você lembra de alguma vez que aconteceu isso?

$\mathrm{R}-\mathrm{s}$, a professora falou q estava errado

$\mathrm{P}$-mas você lembra? me conta!

R- S, pera pegar meu caderno...fui pegar a palavra tigre e sail=tier pavao e saiu=peak

por $\mathrm{q}$ as vezes a palavra sail como se estivese numa frase

Sabemos que nenhum tradutor online é capaz de traduzir corretamente todas as palavras e/ou sentenças por desconhecer o contexto no qual o termo a ser traduzido está inserido. Existem as variações de cada língua e o tradutor não está capacitado para interpretá-las, ele somente oferece a melhor versão para o que foi escrito para tradução. No caso desse aluno, devido à grande semelhança entre as palavras "erradas" que foram obtidas através do tradutor e a maneira correta como são escritas em língua inglesa, podemos inferir que não seria um problema na tradução, mas sim na maneira como foram copiadas da ferramenta, ou seja, o aluno pode ter se confundido e não as transcrito corretamente. Apesar desse apontamento, o aprendiz afirmou que considera o Google Tradutor útil por auxiliá-lo sempre que necessário.

A autonomia também tem sido associada à liberdade do controle do professor, das restrições curriculares e até mesmo liberdade para escolher não aprender (LITTLE, 1991). Contudo, Little (1991) afirma que a liberdade deve fazer parte da autonomia, entretanto, autonomia não significa isolamento, sendo um equívoco afirmar que aprendizes fazem um progresso melhor e mais rápido quando trabalham 
individualmente. Autonomia no aprendizado não significa "ausência de professor" ou "aprender sozinho", embora exista o mito ou crença que relaciona autonomia à aprendizagem isolada, individual e sem a presença do professor. Embora aprendizes autônomos possam trabalhar isoladamente, isto não é uma condição essencial para autonomia. Dessa maneira, observamos que a presença e interferência da professora na sua aprendizagem ainda são essenciais, conforme Little (1991), o aprendiz não é responsável pela totalidade do processo de aprendizagem, pois, de maneira alguma o professor é indispensável.

Partindo para outro ponto, ao ser questionado sobre ter aprendido algo com o Google Tradutor, responde da seguinte forma:

Excerto \# 13

$\mathrm{P}$ - você aprendeu alguma coisa usando o google tradutor?

$\mathrm{R}$ - Sim por q consequi decorar algumas palavras

Por meio dessa asserção, podemos inferir que o tradutor, nesse caso, auxiliou na aprendizagem de palavras da língua inglesa para o indivíduo. Sabemos que a sala de aula não é o único local onde se aprende algo; a aprendizagem pode ocorrer em locais menos ou não formais, como a internet. Além disso, segundo Paiva (2010), os aprendizes de língua estrangeira buscam propiciamentos fora do contexto escolar, pois a escola não oferece recursos suficientes para a aprendizagem de outra língua. Pudemos observar esse fato nesse contexto, pois a escola, mesmo com bons e dedicados professores, não é capaz de fornecer todo o auxílio que o aluno precisa para a aquisição da língua, até mesmo por ter que seguir moldes e modelos pré-impostos pelo sistema educacional. Essa asserção corrobora com Prensky (2001) que acredita que esse sistema não está preparado para atender às necessidades dos alunos da atual geração, os nativos digitais.

Logo após a resposta do excerto 12, ele cita algumas palavras das quais se recorda, comprovando a eficácia da ferramenta para ele nesse estágio inicial do processo de aprendizagem da língua, no qual ele se encontra. Portanto, ela se torna fundamental nesse caso. Assim, conforme Prensky (2001), os ambientes externos à sala de aula podem oferecer condições de criação de diferentes propiciamentos e, como resultado, a aprendizagem.

Relacionado à importância da aprendizagem da língua inglesa, João faz a seguinte consideração: 


\section{Excerto \# 14}

$\mathrm{P}$ - você acha que é importante aprender inglês?

$\mathrm{R}$ - $\mathrm{s}$ por que posso uzar futuramente em uma carreira $\mathrm{q}$ eu posso escolher

$\mathrm{P}$ - você acha que aprender inglês é importante para o seu dia-a-dia?

$\mathrm{R}$-s por q poso ficar perdido em um lugar q as placas estao escritas in ingles

Apesar da inocência percebível no exemplo das placas em inglês, João exemplifica claramente o inglês como língua global. A atual busca de informação aliada à necessidade de comunicação em nível mundial fez com que o inglês fosse promovido como língua global. Ao assumir este papel, torna-se uma das mais importantes ferramentas, tanto acadêmicas quanto profissionais. É hoje, inquestionavelmente, reconhecido como a língua mais importante a ser adquirida na atual comunidade sociedade. $\mathrm{O}$ inglês acabou tornando-se o meio de comunicação por excelência tanto do mundo científico como do mundo de negócios.

Ademais, o possibilita exercitar outra habilidade para a aquisição da língua inglesa, a compreensão auditiva:

\section{Excerto \# 15}

$\mathrm{P}$ - e você escutou o som das palavras lá?

$\mathrm{R}-\mathrm{S}$, ten gelto de por para ouvir

$\mathrm{P}$ - você acha que dá para aprender a falar as palavras repetindo o som delas quando você ouve lá?

$\mathrm{R}-\mathrm{s}$, acho perfeito por $\mathrm{q}$ o som sai direitinho

$\mathrm{P}$ - e você tentou repetir as palavras?

$\mathrm{R}$ - já prinsipalmente quando o som sai ben diferente

O Google Tradutor possui um aplicativo que possibilita ao usuário ouvir as palavras ou sentenças na língua em que foram traduzidas. Ao assegurar que se pode aprender a pronúncia das palavras por meio desse recurso, esse aprendiz efetiva um propiciamento na aprendizagem da língua. Porém, podemos notar que essa ferramenta, mesmo com todos os recursos que ela e a internet possuem, não consegue, ainda, suprir completamente a aprendizagem do João:

Excerto \# 16

$\mathrm{P}$ - e na sala de aula, você consegue aprender a pronúncia das palavras? Ou prefere aprender sozinho no google?

$\mathrm{R}$ - prefiro na sala por q posso tirar duvidas

$\mathrm{P}$ - mas a professora sempre tira as suas dúvidas?

$\mathrm{R}$ - quando agente pergunta sim

$\mathrm{P}$ - mas e agora que você está sem professora?

$\mathrm{R}$ - nao estamos teno aula

$\mathrm{P}$ - você não está tentando aprender nada de inglês? 
$\mathrm{R}-\mathrm{n}$

Através desse excerto, notamos que esse aprendiz parece não se constituir como autônomo no seu processo de aprendizagem. Sem a presença do professor, nesse caso, o aluno encontra-se estagnado em sua aprendizagem de língua inglesa esperando o estímulo de um professor, sem procurar adquirir conhecimento, mesmo que pelo Google Tradutor. Sabemos que a autonomia não é sinônimo de autoinstrução, tampouco um novo método. O aprendiz autônomo é aquele que traça objetivos de acordo com suas necessidades e assume a responsabilidade sobre como, quando e onde estudar para alcançar resultados desejados. Segundo Dickinson (1987), a autonomía na aprendizagem é essencialmente uma questão de atitude para aprender, o que esse aprendiz não aparenta apresentar.

O uso de tecnologias de comunicação e informação aumenta as possibilidades de aprendizagem e, por conseguinte, a autonomia. Porém, Benson (1997) declara que para reconhecer e usufruir o potencial da tecnologia para auxiliar o desenvolvimento da autonomia, é necessário antes estar dentro do processo rumo a autonomia. Notamos que, por não encontrar-se nesse estágio, João não é capaz, apesar de familiarizado com ferramentas digitais, de utilizar as possibilidades do Google Tradutor para a aprendizagem de inglês.

Porém, João se contradiz:

Excerto \# 17

$\mathrm{P}$ - você acha que o google tradutor é importante para te ajudar a aprender inglês?

$\mathrm{R}$ - S por q e um saite muito utilizado e se eu presisar de olhar tirarei minha duvida

$\mathrm{P}$ - sem esses sites que te ajudam a aprender inglês, você acha que seria mais difícil aprender?

$\mathrm{R}$ - s por q nao tenho a profesoora toda hora au meu lado para tirar duvida

Apesar das suas respostas do excerto 15, no excerto acima demonstra ter consciência de que é necessário possuir autonomia sobre seu estudo. De acordo com Paulo Freire (1996), em Pedagogia da autonomia: saberes necessários à prática educativa, a autonomia se constrói durante experiências que são e serão vividas por um sujeito, sendo assim um processo centrado em estimulações e decisões a serem tomadas. Podemos, então, perceber que esse aprendiz percebe de maneira inconsciente esse processo e que, possivelmente, em dado momento o iniciará. 
Ademais, as respostas do aprendiz apresentam a forma como os professores julgam o Google Tradutor:

Excerto \# 18

$\mathrm{P}$ - as professoras de inglês que você já teve, também acham importante? ou não gostam que você utilizem?

$\mathrm{R}$ - Nao por que acham q devemos decorar as palavras en sala de aula

$\mathrm{P}$ - e você concorda?

$\mathrm{R}$ - $\mathrm{s}$ por que e quase a mesma coisa de pegar cola

$\mathrm{P}$ - mas também, como você falou, é uma forma de aprendizagem, né?

$\mathrm{R}$ - s por q eu posso decorar

É interessante a forma como ele expõe o porquê de os professores não gostarem da ferramenta, "[os professores] acham q devemos decorar as palavras em sala de aula". Trata-se de uma crítica ao método - superficial - adotado, e, alem disso, não aceitam que se faça em casa o que é feito dentro de sala de aula, ao usarem a tradução de vocábulos em casa, estariam antecipando o que seria dado na aula. Novamente, notamos um despreparo no sistema educacional para ensinar uma língua estrangeira para a geração dos nativos digitais. A ferramenta Google Tradutor, assim como outras, poderia ser usada em sala de aula, cabendo ao professor selecionar a melhor forma de utilizá-la sem pré-conceitos e visão negativa dos aparatos tecnológicos no ensino de língua estrangeira.

\section{Considerações finais}

Este artigo buscou demostrar, de forma geral, quais ferramentas digitais são utilizadas por aprendizes de língua inglesa do Ensino Fundamental de uma escola da rede pública. Notamos uma familiaridade com diversas ferramentas disponibilizadas na web, o que demonstra, de certa forma, como esses aprendizes se encaixam no perfil de 'nativo digital' proposto por Prensky (2001). Interessou-nos em especial a recorrência de apontamentos de utilização da ferramenta Google Tradutor.

Além disso, o trabalho buscou analisar duas questões principais. A primeira, “quais as características do aprendiz João considerando o conceito de "nativo digital'?" Pudemos perceber, por meio da entrevista realizada, que se trata de um nativo digital iniciante no processo de aprendizagem de língua inglesa que utiliza algumas ferramentas do meio digital, inclusive o Google Tradutor. O artigo buscou analisar ainda quais propiciamentos são efetivados por ele através do ambiente virtual relacionado com o uso do Google Tradutor, relembrando que Paiva (2010) afirma que 
propiciamentos não são propriedades dos ambientes, mas sim da interação entre eles e os usuários. João utiliza o Google Tradutor para realizar trabalhos escolares e, até certo ponto, aprender a língua.

$\mathrm{Na}$ segunda questão, "se o uso dessa ferramenta o constitui como sujeito autônomo em sua aprendizagem de língua inglesa", notamos que, nos relatos da entrevista, o aprendiz João ainda não demonstra grande autonomia nesse processo. Como percebido, esse aprendiz, ainda, apresenta muita dependência do professor em sala de aula, não procurando, portanto, buscar conhecimento sem sua presença. Os indícios de autonomia são o fato de João ter se apropriado da utilização dessa ferramenta após conhecê-la através de indicação de um colega e de, provavelmente, utilizá-la quando está jogando no meio digital. Outro indício importante que demonstra a construção de autonomia de João no espaço escolar é o fato de que, mesmo não fazendo curso de língua, ele é um bom aluno na disciplina língua e compreende a importância dessa língua estrangeira no mundo globalizado que vivemos.

\section{Referências}

ASSIS-PETERSON, A. A.; COX, M. I. P. (Org.). Cenas de sala de aula. Campinas: Mercado de Letras, 2001.

BENSON, P.; VOLLER, P. (Eds.). Autonomy and independence in language learning. New York: Addison Wesley Longman, 1997, p. 18-34.

BRASIL. Parâmetros Curriculares Nacionais: Introdução aos Parâmetros Curriculares Nacionais. Brasília: MEC/SEF, 1997.

Linguagens, códigos e suas tecnologias. Brasília: Ministério da Educação, Secretaria de Educação Básica, 2006.

CRYSTAL, D. Language and the internet. Cambridge, Cambridge University Press. 2001.

. English as a global language. New York: Cambridge University Press, 2003.

DICKINSON, L. Self-instruction in language learning. Cambridge: Cambridge University Press, 1987.

FREIRE, P. Pedagogia da autonomia: saberes necessários à prática educativa. Rio de Janeiro: Paz e Terra, 1996.

GIBSON, J. J. The ecological approach to visual perception. Hillsdale: Lawrence Erlbaum Associates, 1986. 
HOLEC, H. Autonomy and foreign language learning. Oxford: Pergamon, 1981.

LITTLE, D. Learner autonomy: definitions, issues and problems 1. Dublin: Authentic, 1991.

LITTLEWOOD, W. Autonomy: an anatomy and a framework. System, v.24, n.4, p.427-435, 1996.

OLIVEIRA, D. V. De redes sociais a comunidades de prática: um estudo sobre percepção e efetivação de affordances no ambiente on-line. Trabalho de conclusão de curso (TCC) - Letras, Universidade Federal do Triângulo Mineiro, Uberaba, 2011

PAIVA, V. L. M. O. Autonomia e complexidade. Linguagem \& Ensino, vol. 9, n.1, p. 77-127, $2006 . \quad$ Disponível em: $<$ http://rle.ucpel.tche.br/php/edicoes/v9n1/vera_paiva.pdf $>$ Acessado em 15 de outubro de 2011.

Propiciamento (affordance) e autonomia na aprendizagem de língua inglesa In: LIMA, Diógenes Cândido. Aprendizagem de língua inglesa: histórias refletidas. Vitória da Conquista: Edições UESB, 2010.

Affordances beyond the classroom. Disponível em: $<$ http://www.veramenezes.com/beyond.pdf $>$ Acessado em 09 outubro de 2011.

Aquisição e complexidade em narrativas multimídia de aprendizagem.

Revista Brasileira de Linguística Aplicada, v. 8, n. 2. p. 321-339, 2008. Disponível em: <http://www.letras.ufmg.br/rbla/2008_2/03-Vera-Menezes.pdf $>$ Acessado em 22 de outubro de 2011.

O ensino de língua estrangeira e a questão da autonomia. In: LIMA, D. C. (Org.), Ensino e aprendizagem de língua inglesa: conversas com especialistas. São Paulo: Parábola Editorial, 2009.

PRENSKY, M. Digital natives, digital immigrants. On the Horizon, v. 9, n. 5, 2001.

TEMPLE, M. Dicionário Oxford. New York: Oxford University Press, 2007.

VAN LIER, L. The Ecology and Semiotics of Language Learning: a Sociocultural Perspective. Dordrecht: Kluwer Academic Publishers, 2004.

YIN, R. K. Case study research: design and methods. 4 ed. Thousands Oaks, Califórnia: Sage Publications, 2009.

Artigo recebido em: 29.09.2012

Artigo aprovado em: 17.12.2012 